\title{
Case Report on Ewing's Sarcoma - A Defaulter Stepped into Metastasis
}

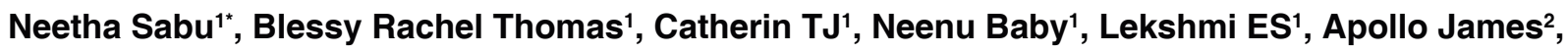 \\ T Sivakumar $^{3}$
}

1'Department of Pharm.D intern, Nandha College of Pharmacy, Erode, Tamil Nadu, INDIA.

${ }^{2}$ Department of pharmacy practice, Nandha College of Pharmacy, Erode, Tamil Nadu, INDIA.

${ }^{3}$ Department of pharmaceutical analysis, Principal, Nandha College of Pharmacy, Erode, Tamil Nadu, INDIA.

\begin{abstract}
Ewing's sarcoma is a very rare type of malignant tumour that grows in bones or the soft tissue around the bones, such as cartilage or the nerves. It usually affects people from the ages of 10 to 20 and has a high rate of being cured. Children with Ewing's sarcoma that hasn't spread have cure rates as high as $80 \%$. Even if the treatment works, patients still need to follow up for many years. Ewing's sarcoma can return even a decade after the diagnosis. This is a case of 9-year-old male patient with a known case of Ewing's sarcoma diagnosed 3 years back. He was treated according to National Comprehensive Cancer Network recommendations for Ewing's sarcoma and later he defaulted for 1 year. Now he is at the stage of metastasis of Ewing's sarcoma. The study points out that there is an utmost importance of regular follow ups and therapeutic value of completing the treatment.
\end{abstract}

Key words: Ewing's sarcoma, Defaulter, Metastasis, Chemotherapy.

Arthur Purdy Stout in 1918, found a new type of tumour composed of small round cells with rosettes which he named as primitive neuroectodermal tumor (PNET). Later, James Ewing found a radiosensitive tumour of long bones with undifferentiated cells ${ }^{(2)}$ (Ewing's sarcoma). Both these tumours are found at the bones and soft tissues.

Ewing's sarcoma is an extremely rare cancerous tumour that is usually seen in diaphysis of long bones and in flat bones. ${ }^{(1)}$ It also originates from the pelvic bones and ribs. Skull bones, the vertebra, the scapula, and the small bones of hands and feet are some of the other less-frequent and rare locations. It can also affect any soft tissues ${ }^{[9]}$ This disease mainly develops in the first and second decade of life.(1) The origin of the tumour is thought to be primitive cell derived either from embryological tissue called the neural crest or from the mesenchymal stem cells..$^{[2,3]}$

For a long period of time Ewing's sarcoma was thought to be derived from primitive neuroectodermal cells. Later on, substantial research indicated that mesenchymal cells (MSC) may be the original progenitor of Ewing's tumour. ${ }^{[17]}$

Ewing's sarcoma is also thought to be the result of a non-random chromosomal translocation EWS gene on chromosome 22 and other ETS genes. Most common of this is the translocation with the FL11 gene on chromosome 11. ${ }^{[18,19]}$ A reciprocal inversioninsertion- translocation mechanism that gives out a EWS-ERG fusion is also thought to be a cause ${ }^{[20]}$

The local symptoms that is seen in patients with Ewing's sarcoma are tumour mass formation, pain, swelling, venous dilation, hyperaemia. Pathological fractures can be seen in case of bone metastasis and back pain in spinal metastasis which can lead to spinal paralysis. ${ }^{[12,13]} \mathrm{It}$ is an aggressive cancer which tend to recur where it arose and spread throughout the body (metastasis).
DOI: 10.5530/ijopp.10.4.62

Address for correspondence: Neetha Sabu, Nandha college of Pharmacy, Erode.

Phone no: 9605498564

Email Id: nsabu9@gmail.com

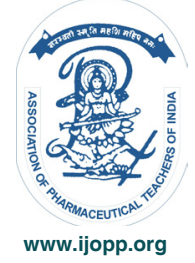




\section{Diagnosis}

The best mode of diagnosis is biopsy. EFT cells show membranous expression of CD99 or MIC2 on immunohistochemistry ${ }^{[10]}$ Other findings include:

- Radiographs that show large destructive lesion in the diaphysis or metaphysis or lesion that are purely lytic or have variable amounts of reactive new bone formation

- Bone scan that show bone lesions

- MRI is required as initial staging workup to identify soft-tissue extension and marrow involvement

- CT chest for initial staging of pulmonary metastasis

There are three potential types of therapy: chemotherapy, radiation therapy and surgery. ${ }^{[3,4]}$ Treatment become successful only when systemic chemotherapy is used in conjunction with surgery or radiation therapy. ${ }^{[5,6]}$ Vincristine, Doxorubicin, Ifosfamide and Etoposide are the multidrug chemotherapy for Ewing's sarcoma. Cyclophosphamide and Dactinomycin are also preferred by some protocols. ${ }^{[7]}$ Patients having metastasis show good initial response to preoperative chemotherapy, but in most cases, it is partially controlled and in some cases, it reoccurs. ${ }^{[8]}$

\section{Assessment}

After chemotherapy, excision specimens are collected and examined to assess necrosis that can predict the prognosis. The histological response to chemotherapy is graded as:

- Grade 1 indicates $50 \%$ or less of tumour necrosis

- Grade 2 is more than $50 \%$ but less than $90 \%$ necrosis

- Grade 3 is $90-99 \%$ necrosis, and

- Grade 4 is $100 \%$ necrosis.

Superior local recurrence-free survival is expected for 5 years if the responses to chemotherapy grades are 3 and $4 \cdot[9,14]$

We are reporting a case of defaulter who ended up in metastatic stage which spreaded to right common iliac, right external iliac, right inguinal lymph nodes and multiple bones.

9-year-old male was presented with increased swelling over right fibula for few weeks. 3 years back patient was found to have CD 99 focal positivity and biopsy showed features of Ewing's sarcoma. The patient received 3 cycles of VAC/IE chemotherapy and later in the following year, he underwent excision of upper $2 / 3^{\text {rd }}$ of right fibula with primary closure. Further histopathological examination showed no residual tumour mass and continued VAC/IE up to 5 cycles. Patient was a defaulter after chemotherapy for 1 year and Ewing's sarcoma reoccurred the next year. MRI showed $6.2 \times 12.1 \mathrm{~cm}$ tumour and CT chest showed normal study.

In the present year, $\mathrm{TC}^{95 \mathrm{~m}}$ study showed primary bony lesion in cristae third of right fibula. The patient received 2 cycles of ICE chemotherapy. Patient also received 31 cycles of radiation therapy of 1.8 gray units.

As the patient came with complaints of increased swelling, PET-CT scan was suggested. Laboratory investigations were mentioned in the Table 1.

On the day of admission, patient had pain and increased swelling over right leg, tenderness in entire thigh. His local examination showed swelling and tenderness present over right lower limb with skin changes, scrotal swelling (+) - inguinal lymph node approximately $1 \mathrm{~cm}$ palpable. On general examination the patient was pallor. He was treated with Inj Morphine $0.3 \mathrm{ml}$ iv per h our (infusion-1 $\mathrm{ml}+9 \mathrm{ml}$ normal saline), Tab.Trimethoprim +Sulfamethoxazole $80 / 400 \mathrm{mg}$ twice a day(day (alternate days), Inj. Paracetamol $250 \mathrm{mg}$ four times a day, Chlorhexidine mouth wash thrice daily, Betadine oinment perianal twice a day . On the $2^{\text {nd }}$ day, the pain was reduced with the treatment. Same treatment was followed with $70 \mathrm{ml} / \mathrm{hr}$ Normal Saline. On $3^{\text {rd }}$ day PET-CT scan was donedone, and patient was complaining of pain in right lower limb and had a mild fever. Inj. Morphine was changed to Tab. Morphine $5 \mathrm{mg}$ every $6^{\text {th }}$ hourly and continued with other drugs.

PET-CT showed hyper metabolic mass lesion involving the posterior compartment of distal thigh and right proximal leg suggestive of residual / recurrent primary tumour metastasis to right common iliac, right external iliac, right inguinal lymph nodes and multiple bones.

Final diagnosis of the patient was found to be recurrent Ewing sarcoma right fibula with multiple bony and lymph node metastasis. Patient was discharged with chemotherapy and supportive therapy as mentioned in Table 2 and Table 3.

\section{DISCUSSION AND CONCLUSION}

In this case report, the patient was diagnosed with Ewing's 
sarcoma 3 years before and started chemotherapy. Surgery was done and HPE showed no residual tumour mass. He was a defaulter for the following year. After 1 year, he came to hospital with complaints of swelling and pain over right leg. In MRI scan it was found that Ewing's sarcoma reoccurred and underwent treatment. In the present state, patient is having increased pain and swelling over the right fibula, thigh and scrotal area. In PET-CT scan it was found that the sarcoma metastasized to other parts of the body.

From the above study, it is concluded that primary and metastatic sites should be examined every 10-12 weeks during therapy and 3-4 months during the first year after therapy, and also points out the therapeutic value of completing the treatment.

Also, it is suggested that after the completion of therapy re-evaluations should be done every 5-6 years. Even if these evaluations show disease free remission an annual follow up is recommended.

\section{CONFLICT OF INTEREST}

Authors state that there is no conflict of interest.

\section{ACKNOWLEDGEMENT}

We would like to thank Prof.Apollo James and Dr.Sirisha Yadavalli for extending their helping hand.

\section{ABBREVIATIONS}

NCCN: National Comprehensive Cancer Network; CD 99: Cluster of Differentiation 99; VAC/IE: Vincristine,Adriamycin (doxorubicin), Cyclophosphamide/Ifosfamide, Etoposide; PETCT: Positron Emission Tomography-Computed Tomography; MRI: Magnetic Resonance Imaging; TC 95m: Technetium 95m; ICE: Ifosfamide, Cyclophosphamide, Etoposide; HPE: Histopathological examination; EFT: Ewing's family of tumors; PNET: Primitive Neuroectodermal Tumor; ETS: E 26 Transformation specific.

\section{REFERENCE}

1. Nithin A, Aamir BS. Ewings sarcoma of the calcaneous with metastasis to the tibia and fibula. Acta Orthopaedica Belgica. 2008;74(2):270-2.

2. Balamuth NJ,Womer RB. Ewings sarcoma.Lancet oncol. 2010:11;184-92.

3. Lor R,George C, Holly S, Stephen L. Ewing's Sarcoma Family of Tumors (ESFT). The Liddy Shriever Sarcoma Initiative.2011/2

4. Maheshwari AV, Cheng EY. Ewing sarcoma family of tumors. J Am Acad Orthop Surg. 2010:18(2);94-107. Review.

5. Craft A,Cortterill S, Malcolm A, et al. Ifosfamide-containing chemotherapy in Ewing's sarcoma: The Second United Kingdom Children's Cancer Study Group And The Medical Reaserch Council Ewing's Tumour Study. J Clin oncol.1998;16(11):3628-33.

6. Juergens C, Weson C, Lewis. et al. Safety assessment of intensive induction with vincristine, ifosfamide, doxorubicin and etoposide (VIDE) in the treatment of ewing tumours in the EURO-E.W.I.N.G.999 clinical trial. Pediatr Blood Cancer. 2006;47(1):22-9.

7. Paulussen M, Craft AW, Lewis I, et al. Results of the EICESS-92 study : two randomised trials of Ewing's sarcoma treatment-cyclophosphamide compared with ifosfamide in standard risk patients and assessment of benefit of etoposide added to standard treatment in high-risk patients.J clin oncol. 2008;26(27):4385-93.

8. Ladenstein R, Potschger $U$, Le Deley $M C$, et al. Primary disseminated multifocal Ewing's sarcoma:Results of the Euro-EWING 99 trial.j clin oncol. 2010;28(20):3284-91.

9. Saral SD, Nirmala AJ. Pathology of Ewing's sarcoma/PNET: Current opinion and emerging concepts. Indian Journal of Orthopedics. 2010;44(4):363-8.

10. Khoury JD. Ewing sarcoma family of tumors. Adv Anat Pathol. 2005:12;212-20.

11. Patrick O'Donnell.Ewing's sarcoma.Ortho bullets. 2011.

12. Patterson FR, Basra SK. Ewing's sarcoma. In: Schwartz HS,Editor.Orthopedic knowledge update:Musculoskeletal tumours 2. Rosemont: American Academy of Orthopaedic Surgeons. 2007:175-83.

13. Toshifumi O. Diagnosis and treatment of Ewing's sarcoma of the bone:Review article. Journal of Orthopaedic Science. 2015;20(2):250-63.

14. Lin PP, Jaffe N, Herzog CE, Costelloe CM, Deavers MT, Kelly JS, et al. Chemotherapy response is an important predictor of local recurrence in Ewing sarcoma. Cancer. 2007:109;603-11.

15. Tirode F, Laud-Duval K, Prieur A, et al.,"Mesenchymal stem cell features of Ewing tumour," cancer cell. Elsevier. 2007;11(5):421-9.

16. Ordonez JL, Osuna D, Herrero D, et al. "Advances in Ewing's sarcoma research: Where are we now and what lies ahead?". Cancer Research. 2009;66(18):7140-50.

17. Downing JR, Head DR, .Parham DM, et al., "Detection of the $(11 ; 22)$ (q24-q12) translocation of Ewing's sarcoma and peripheral neuroectodermal tumour by reversed transcription polymerase chain reaction". American Journal of Pathology. 1993;143(5):1294-1300

18. Maire G, Brown CW, Bayani J, et al. "Complex rearrangement of chromosomes 19,21 and 22 in Ewing's sarcoma involving a novel reciprocal inversioninsertion mechanism of EWS -ERG fusion gene formation: a case analysis and literature review". Cancer Genetics and Cytogenetics. 2008;181(2):81-92. 